Nigerian Journal of Environmental Sciences and Technology (NIJEST)

www.nijest.com

ISSN (Print): 2734-259X ｜ＩSSN (electronic): 2734-2603

Vol 5, No. 1March 2021, pp 140 - 151

\title{
Models for Estimating the Hearing Threshold of Quarry Workers at High Frequencies
}

\author{
Akanbi O. G. ${ }^{1}$, Oriolowo K. T. ${ }^{2}$, Oladejo K. A. ${ }^{3 *}$, Abu R. ${ }^{4}$, Mogbojuri A. O. ${ }^{5}$ \\ and Ogunlana R. ${ }^{6}$ \\ ${ }^{1,2}$ Department of Industrial and Production Engineering, University of Ibadan, Nigeria \\ ${ }^{3}$ Department of Mechanical Engineering, Obafemi Awolowo University, Ile Ife, Nigeria \\ ${ }^{4}$ Department of Mechanical Engineering, University of Ibadan, Nigeria \\ ${ }^{5}$ Department of Mechanical Engineering, Yaba College of Technology, Yaba, Nigeria \\ ${ }^{6}$ Department of Mechanical Engineering, Adeseun Ogundoyin Polytechnic, Eruwa, Nigeria \\ Corresponding Author:*wolesteady@yahoo.com
}

https://doi.org/10.36263/nijest.2021.01.0254

\begin{abstract}
It is widely known that quarry industry has great importance in developing countries, such as Nigeria. There is paucity of information regarding effects of noise experienced by quarry workers during their working time. Therefore, this study investigated the influence of age of workers, years of exposure of workers and noise level of the machine used in quarry on hearing threshold. A factorial design of experiment was employed for the investigation. Two hundred and four quarry workers volunteered for this study from four quarries in South western Nigeria. Emitted noise, which quarry workers were exposed to during machinery operation, was measured with a digital sound level meter and workers hearing threshold was measured in an audiogram sound proofing testing booth at standard conditions. Predicted models were established from experimental design to determine main and interactions effects towards the response (hearing threshold). These were statistically analysed using analysis of variance (ANOVA). All terms of the models were significant at $p<0.05$. The best fitted model was at $4 \mathrm{kHz}\left(R^{2}=0.639, p<0.05\right)$. The magnitudes of the main effect of the factors are in ascending order of noise level $>$ years of exposure $>$ age. The analysis of the experimental response indicated that there is no interaction of any factors on the hearing threshold. It can be concluded that age, years of exposure and noise level have main effects at various capacities at different frequency to predict the hearing threshold of the quarry workers. This work determined the factors and the predicted model to spell out safe hearing threshold of quarry workers that fitted for the job at a particular noisy workstation as well as ensuring comfortable, safe and effective workstation design.
\end{abstract}

Keywords: Factorial design, Safe hearing threshold, Quarry workers, Noise level, High frequency

\subsection{Introduction}

In the industrial sense, noise usually means excessive sound or harmful sound (Al-Maghrabi et al., 2013). Sound is generally understood as a pressure wave in the atmosphere. Human sense of hearing can detect both of these characteristics. Pressure intensity is sensed as loudness, whereas pressure frequency is sensed as pitch. For human being hearing perception, low frequency noise is 250 Hertz $(\mathrm{Hz})$ and below. High frequency noise is $2000 \mathrm{~Hz}$ and above. Mid-frequency noise falls between 250 and $2000 \mathrm{~Hz}$.The formal recording of an individual's hearing forms the basis of the audiogram. Auditory sensitivity is usually assessed by means of Pure Tone Audiometry, which measures the lowest detectable sound levels at different frequencies. This measurement may reflect the loss of sensitivity to weak sounds (Lobarinas et al., 2013) an individual's threshold hearing to pure tones at different frequencies $(250-8000 \mathrm{~Hz})$ is performed.

The workers exposure time weighted average for high noise level working environment, requires the wearing of earplugs and earmuffs all together. Proper insertion of earplugs in the ears is the only guarantee to efficacy of the earplugs. Earmuffs have higher noise reduction rating than earplugs (Abe 
et al., 2009).The most important factor in selecting a type of noise protection is probably effectiveness in reducing decibel level of noise exposure. The workers' comfort factor goes beyond the simple goal of promoting worker satisfaction. If workers find a type of ear protection uncomfortable or awkward to wear they will use every excuse not to wear it, which results in loss of protection. Due to ever increasing level of industrialization, industrial noise is an ever growing problem. It is very important to be able to quantify and control this noise and thus its effects on man and its environment. This can be better achieved if planning ahead of an envisaged potential danger which may be caused eventually if not controlled. Although normally, individual noise is one of the less prevalent community noise problems, neighbours of noisy manufacturing plants can be disturbed by sources such as fans, motors, compressors etc. mounted on the outside building (Ojolo and Ismail, 2011).

The prevalence of hearing loss increases with age (Akeroyd, 2014). Excessive sound is one of the most common causes of hearing loss. The hazardous effects of noise on hearing have been studied for over a century. Over the past few decades, considerable attention has been given to the mechanisms and features of noise induced hearing loss (Solanki et al., 2012). The sound levels in urban communities are apparently rising, and the nuisance value of unwanted sound is greatly increased (Karvana et al., 2012). The most serious pathological effect of noise on man is hearing loss leading to complete deafness. The victim is generally unaware of it at the early stages. It is unfortunate that workers failed to realize that the repeated and continuous exposure to noise above $90 \mathrm{dBA}$ may result in permanent hearing loss. Noise Induced Hearing Loss (NIHL) initially affects the frequencies of 6 , 4 , or $3 \mathrm{kHz}$, and with the progression of the loss, it can reach the regions of $8,2,1 \mathrm{kHz}, 500$ and $250 \mathrm{~Hz}$. Moreover, the individual can have tinnitus and discomfort related to intense sounds, and once the noise exposure ends, there is no more hearing loss progression (Hong et al., 2013; England and Larsen, 2014; Biassoni et al., 2014). Noise induced damages amount to approximately 4 million dollars per day (McBride, 2004; Williams et al., 2004). Tinnitus can be defined as an auditory illusion, or sound sensation unrelated to the external source of stimulation. This is frequently related to hearing loss, but it is also known to be presented in individuals without apparent hearing loss (Ibraheemm and Hassaan, 2016). When susceptible, unprotected ears are exposed to loud noise potentially injurious to hearing, the inner ear seems to react in one of three ways: by adapting to the noise (i.e. the inner ear seems to "toughens" in some individuals), by developing a Transient Threshold Shift (TTS) or a Permanent Threshold Shift (PTS) (England and Larsen, 2014). TTS refer to a transient sensorineural hearing loss lasting hours to a few days. Hearing thresholds are depressed until the metabolic activity in the cochlear recovers. For this reason, workers ideally should be out of noise for at least 24hours if not 48hours prior to audiometric testing to avoid the effects of TTS on hearing. PTS refers to a permanent loss of sensorineural hearing which is the direct result of irreparable injury to the organ of Corti. Noise induced deafness generally affects hearing between $3000-6000 \mathrm{~Hz}$ with maximal injury centring around $4000 \mathrm{~Hz}$ initially, an important point to remember.

As age affects sensitivity to the high frequencies of noise is lost first and the loss is irreversible. In audiometry, such loss is described as a permanent threshold shift. Audiometric testing consists of determination of the minimum intensity (the threshold) at which a person can detect sound at a particular frequencies is lost as a result of age or damage, the intensity at which a stimulus can be detected increases. It is in this sense that hearing loss can be described as a threshold shift. Studies have shown age decrements in performance of sustained attention tasks. Onder et al., (2012) studied NIHL in mines at Turkey. They had applied statistical analysis (hierarchical log-linear) of the data. Data were collected from a quarry and stone crushing screening plant. According to their study, the risky occupation job group of the places surveyed was the drivers and this job group had high possibility of exposure to $70-79 \mathrm{dBA}$ noise levels. The drivers, especially of the $46-54$ years age group, had experienced NIHL. When the important interactions in the analyses were evaluated, it was found out that 4-11 years experienced crusher workers working in the stone crushing - screening plants had high probability of NIHL because of high exposure to 90 - 99dBA noise level. Bouloiz et al., (2013) presented an analysis, by a combination of dynamic systems and fuzzy logic, of the work environment of human factor. This environment contains a set of factors (variables) that influence human behaviour in the context of industrial safety. Fuzzy logic is used to account the qualitative and uncertain nature of variables value resulting from the phenomenon of perception. The fuzzy logic was used for modelling the safe behaviour of human factor. 
Ojolo and Ismail (2011) modelled the effects of noise on machine operators. Major hearing losses were traced to noise generated by machinery. The results showed that hearing loss increases with increase in frequency and age; and is influenced by the loudness level and sound intensity. Fourth order Newton difference scheme was used in modelling; the result was simulated using MATLAB program with the operator's age as the major factor. Other effects are indirect health, psychosocial and economic effects which can lead to social isolation and reduced quality of life (Bainbridge and Wallhagen, 2014; Mick et al., 2014; Kamil and Lin, 2015). Older persons with hearing loss are prone to hospitalization (Genther et al., 2013), death (Contrera et al., 2015; Fisher et al., 2014), as well as higher rates of dementia (Lin et al., 2011; Gallacher et al., 2012), and depression (Li et al., 2014; Mener et al., 2013), even when known risks for these abnormality are considered. (Lin et al., 2011; Allen and Eddins, 2010) stated that annual health care costs for middle-age United States of America adults with hearing loss are significantly higher than the costs of care for those without hearing loss. Person with hearing loss achieve lower level of education and cognition than those with normal hearing, higher unemployment level or underemployment which may results to lower income level than those with normal hearing (Starr and Rance, 2015).

There are two major methods used for analysing the variables: classical and statistical. The former method is a conventional method approach, involves varying one independent variable at a time, (OVAT), or one-factor-at-a-time, (OFAT) has been found to be useful to observe the individual effects on certain components and process conditions. It is however, lacking in predicting the interaction and interrelationship between the various components influencing the realization of a particular response(s). But found to be full of bias, tiring, and time consuming by having too much experimental runs. This is further argued by the fact that variable cannot be studied by varying one factor at a time, as it often does not allow determination of actual optimum level of different components, as well as identification of vital factors affecting a system or process (Ridzuan and Yacoub, 2016). The latter methods which include factorial experiments, provides an alternative approach through screening of a particular process by considering individual or linear and mutual interactions among the variables and give an estimate of the combined effect of these variables on the final results.

Though many research work has been done in the area of the factors affecting hearing threshold (age, years of exposure and noise level), but this work is yet to come across the degree of contributions of each independent variable factors to the dependent factors. In lieu of this observation, this work will analyze the contributions of age, years of exposure and noise level to the hearing threshold at each frequency by applying factorial experimental statistical design to screen the main and interactions effects of the independent variables on the dependent variables. Following are the objectives of this study:

- To estimate the amount of noise emitted by various heavy earth moving machineries which workers are exposed to during working hours in a stone quarry

- To develop a predictive model of occupational noise impact on quarry workers.

- To determine contribution of each of independent variables (age of workers, years of exposure and noise level) on the dependent variable (hearing threshold) as well as their interactive effects.

\subsection{Materials and Methods}

\subsection{Subject selection}

Four quarry sites were selected for this study. Two hundred and four workers volunteered for this study for the first research arrangement in the month of June - July, 2017. The permission of the quarry management was obtained prior to the start of the study. Participants from different sections in each quarry were selected and were notified several days before the commencement of the study, given consent form to sign and questionnaire answered before data collection began. All tools and equipment used in this study were evaluated using standard procedures, pretested and revised to ensure their validity and reliability to ensure uniformity in the administration of the data from the study. The workers in this study had completely rested for 48 hours or more after their day shift in order to prevent transient hearing loss. 


\subsection{Noise measurement}

This study considered the operators that are exposed directly to the following noise emitted equipment: Primary Crushers, Secondary Crushers, Dumpers, Payloader, Wagon drilling machine, Lathe, Drilling Machine and Excavator. Their operations were used in categorizing the workers into seven groups: Primary Crusher, Secondary Crusher, Compressor, Dumper, Wagon Drilling, Pay loader, Lathe, Drilling Machine and Excavator operators and Administrative staffs. Digital Sound Level Meter (TESTO 815) with sound calibrator (TESTO 0554.0452) which was used to calibrate the sound level meter to the appropriate level, in conformity to the American National Standard Institute, ANSI, and Standard SI. 4 - 2006 was used for the noise emitted by the machine in the quarry. It consists of a microphone that converts sound pressure variations into electrical signals, a frequency selective amplifier, a level range control, frequency weighting to shape the frequency response of the instrument, and an indicator. The reading was then compared with the calibrator's value. The sound level meter was adjusted when required to bring it into calibration. For each particular application, the measurement technique was carefully chosen and controlled to obtain valid and consistent results. Aweighted frequency scales with fast response setting; Type 1 Sound Level Meter was used in this work since it measures how noise fluctuates over time rather than noise exposure.

\subsection{Audiometric testing}

Audiometric test was conducted in an audiogram sound proofing testing booth (TRIVENI TAM -10 5100B) (Howard et al., 2017), on each subject at the hospital in Ibadan by a specialist. Ambient noise met the American National Standards Institute S3.1 standards for maximum permissible ambient noise levels. Audiometric air conduction tests were performed by pre-setting a pure tone at the frequencies of $250,500,1000,2000,3000,4000,6000$ and $8000 \mathrm{~Hz}$ at $5 \mathrm{dBA}$ intervals to the ear of the participant through an earphone. These are the conventional sound frequencies related to the human auditory system. The hearing threshold $(\mathrm{dB})$ was recorded at the frequency at which a particular lowest tone was perceived and the participants respond. Hearing was considered normal if the threshold level was less than or equal to $25 \mathrm{dBA}$ at a frequency (Gallacher et al., 2012; Fisher et al., Kamil and Lin, 2015; Ibraheemm and Hassan, 2016; Howard et al., 2017). The intensity of the stimuli was increased beyond $25 \mathrm{dBA}$ at any frequency until a response was obtained. Intervals of 5 seconds duration were maintained between the tones. The duration of the pre-set tone was $1-3$ seconds. The total time used to perform the audiometric test on a subject was $3-5$ minutes.

\subsection{Factorial design for screening parameters affecting hearing threshold}

In this study, three factors: age, years of exposure, and noise level were selected and screened for their effect on hearing threshold using a multilevel $1^{\wedge} 3^{\wedge} 4^{\wedge} 5$ full factorial design. Selection of the factors was based on previous research from several articles based on one factor at a time (OFAT). Table 1, 2 and 3 shows the coded value of independent variables. The factorial design of Experimental Design SPSS 23.0 was used to design and analyse the experimental data. Each variable effects and interactions on the hearing threshold was statistically determined. A first-order polynomial model that can estimate the main effects of the experimental factors as well as interactive effects is appropriate for modelling (Onsekizoglu et al., 2010). The first-order model with interaction terms proposed for each response variable $\mathrm{Y}$ was based on the multiple linear regression method. A p-value for a given factor less than 0.05 (95\% confidence interval) was considered as significant. For three factors system, a polynomial equation model was used to predict the response of hearing threshold to the selected variables:

$Y=\beta_{0}+\beta_{1} x_{1}+\beta_{2} x_{2}+\beta_{3} x_{3}+\beta_{12} x_{1} x_{2}+\beta_{13} x_{1} x_{3}+\beta_{23} x_{2} x_{3}$

where,

$\beta_{0}$ was the constant term, $\beta_{1}, \beta_{2}, \beta_{3}$ are the main effects, $\beta_{12}, \beta_{13}, \beta_{23}$ are the interaction effects, and statistically non-significant terms were eliminated by stepwise deletion. Regression analyses of the residual values, analysis of variances, normal probability plot were used to evaluate the goodness of fit of the models and significance of each regression coefficient. F-test was used to test for the statistical significance. 
Table 1: Codes, ranges and age classifications

\begin{tabular}{|l|c|l|}
\hline Code & Levels of age (years) & Classification \\
\hline 1 & $15-30$ & Young age \\
\hline 2 & $31-50$ & Middle age \\
\hline 3 & $51-70$ & Senior age \\
\hline
\end{tabular}

Table 2: Codes, ranges and years of exposure classifications

\begin{tabular}{|l|c|l|}
\hline Code & Levels of years of exposure & Classification \\
\hline 1 & $0-10$ & Short term \\
\hline 2 & $11-20$ & Medium term \\
\hline 3 & $21-30$ & Long term \\
\hline 4 & $30+$ & Very long term \\
\hline
\end{tabular}

Table 3: Codes, ranges and noise levels classifications

\begin{tabular}{|l|c|l|}
\hline Code & Levels of noise level & Classification \\
\hline 1 & $25-45$ & Low \\
\hline 2 & $46-65$ & Medium \\
\hline 3 & $66-85$ & High \\
\hline 4 & $86-105$ & Very high \\
\hline 5 & $105+$ & Extremely high \\
\hline
\end{tabular}

\subsection{Results and Discussion}

\subsection{Noise measurement at various facilities under study}

The four understudied quarries had different production units with more or less of the same type of machinery. The noise measurement values were in the range of $87.3 \mathrm{dBA}$ to $116.98 \mathrm{dBA}$, which implies that the noise levels produced exceed the limiting threshold level of $85 \mathrm{dBA}$ except in administrative block.

\subsection{Mean hearing threshold level of respondent}

The mean hearing threshold among all workers in the quarry was $27.9 \mathrm{dBA}$ and 105 respondents $(51.7 \%)$ had hearing threshold higher than $25 \mathrm{dBA}$. The differences between the mean values of hearing threshold level of the respondent of the four quarries are not significant (one-way ANOVA). Thus, the respondents at all the quarries were subjected to about the same working conditions and environmental noise levels.

3.3. Effect of factors of age, years of exposure and noise level on hearing threshold at frequency 3 $\mathrm{kHz}$

Table 5 shows that main effect of Years of exposure $F$ - value $\left(\mathrm{F}_{\mathrm{VE}}\right)=3.608, \mathrm{p}=0.015$ and Noise level F- value $\left(\mathrm{F}_{\mathrm{NL}}\right)=3.553, \mathrm{p}=0.008$, are significant $\left(\mathrm{R}^{2}=0.448, \mathrm{p}<0.05\right)$ with large effects that accounted for $52.8 \%$ of the variability in hearing threshold at $3 \mathrm{kHz}$. Years of exposure has the highest contribution of $29.9 \%$ as shown in Table 6. None of the factors interactions are significant. The normal probability curve of residual is considerably linear, which suggested the adequacy of the model.

The model equation:

$H T=3.70+0.0551 V E+0.233 N L$

where,

HT is the Hearing Threshold.

The model is appropriate for the data as the normal probability plot of residual is approximately linear as shown in Figure 1. 
Table 5: Analysis of Variance (ANOVA) of the independent variables at frequency $3 \mathrm{kHz}$

\begin{tabular}{|l|c|c|c|c|c|}
\hline Source & Sum of square & df & Mean square & F & P value \\
\hline Corrected Model & 7233.342 & 22 & 328.788 & 6.189 & $.000^{*}$ \\
\hline Intercept & 63632.906 & 1 & 63632.906 & 1197.826 & $.000^{*}$ \\
\hline VE & 755.058 & 3 & 251.686 & 3.608 & $.015^{*}$ \\
\hline NL & 574.951 & 4 & 143.738 & 3.553 & $.008^{*}$ \\
\hline VA & 262.920 & 2 & 131.460 & 2.475 & .087 \\
\hline VE*NL & 704.385 & 7 & 100.626 & 1.894 & .073 \\
\hline VE*VA & 23.834 & 2 & 11.917 & .224 & .799 \\
\hline NL*VA & 197.282 & 3 & 65.761 & 1.238 & .298 \\
\hline VE*NL*VA & .000 & 0 & & & \\
\hline Error & 8924.773 & 168 & & 53.124 & \\
\hline Total & 494959.000 & 191 & & \\
\hline Corrected Total & 16158.115 & 190 & & \\
\hline \multicolumn{7}{|c|}{ R Squared = .448 } & & \\
\hline
\end{tabular}

VA, VE and NL are independent variables of age, years of exposure and noise levels respectively

Table 6: Factor effect estimates and sums of squares for the independent variables at frequency $3 \mathrm{kHz}$

\begin{tabular}{|l|c|c|c|c|}
\hline Factor & Regression coefficient & Effect estimate & Sum of square & $\%$ contribution \\
\hline VE & 0.551 & 1.102 & 755.058 & 29.98 \\
\hline NL & 0.233 & 0.466 & 574.951 & 22.83 \\
\hline VA & 0.057 & 0.114 & 262.920 & 10.44 \\
\hline VE*NL & -0.002 & -0.004 & 704.385 & 27.97 \\
\hline VE*VA & 0.002 & 0.004 & 23.834 & 0.95 \\
\hline VE*NL*VA & $-1.05 E-5$ & $-2.11 E-5$ & 0.000 & 0.00 \\
\hline
\end{tabular}

VA, VE and NL are independent variables of age, years of exposure and noise levels respectively

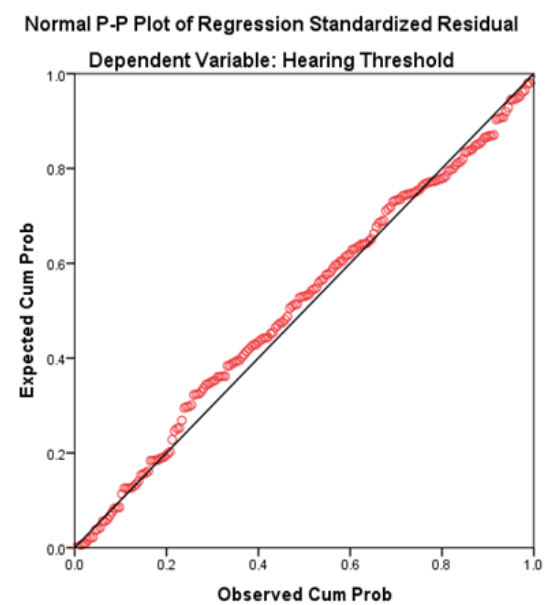

Figure 1: Normal probability plot of standardized residual dependent variable at frequency $3 \mathrm{kHz}$

3.4. Effect of factors of age, years of exposure and noise level on hearing threshold at frequency $4 \mathrm{kHz}$

Table 7 shows that Age $F$ - value $\mathrm{F}_{\mathrm{VA}}=6.135, \mathrm{p}=0.003, \mathrm{~F}_{\mathrm{VE}}=9.108, \mathrm{p}=0.000$ and $\mathrm{F}_{\mathrm{NL}}=8.464, \mathrm{p}=$ 0.000 , have main effects on the hearing threshold and are significant $\left(R^{2}=0.639, p<0.05\right)$. Table 8 shows $79.7 \%$ of the variability of the factors in hearing threshold at $4 \mathrm{kHz}$. Years of exposure have the highest contribution of $36.73 \%$ followed by Noise level with $29.64 \%$. None of the factors interactions are significant. The model equation:

$H T=20.579-0.418 V A+0.383 V E+0.197 N L$

where,

HT is the Hearing Threshold. 
Table 7: Analysis of Variance (ANOVA) of the independent variables at frequency $4 \mathrm{kHz}$

\begin{tabular}{|l|c|c|c|c|c|}
\hline Source & Sum of square & df & Mean square & F & P value \\
\hline Corrected Model & 23718.432 & 22 & 1078.111 & 13.504 & $0.000^{*}$ \\
\hline Intercept & 98141.058 & 1 & 98141.058 & 1229.277 & $0.000^{*}$ \\
\hline VE & 2702.947 & 3 & 900.982 & 9.108 & $0.000^{*}$ \\
\hline NL & 2181.511 & 4 & 545.378 & 8.464 & $0.000^{*}$ \\
\hline VA & 979.573 & 2 & 489.786 & 6.135 & $0.003^{*}$ \\
\hline VE*NL & 1104.957 & 7 & 157.851 & 1.977 & 0.061 \\
\hline VE*VA & 93.197 & 2 & 46.599 & 0.584 & 0.599 \\
\hline NL*VA & 297.497 & 3 & 99.166 & 1.242 & 0.296 \\
\hline VE*NL*VA & .000 & 0 & & & \\
\hline Error & 13412.521 & 168 & 79.836 & & \\
\hline Total & 844496.000 & 191 & & & \\
\hline Corrected Total & 37130.953 & 190 & & \\
\hline
\end{tabular}

VA, VE and NL are independent variables of age, years of exposure and noise levels respectively

Table 8: Factor effects estimates and sums of squares for the frequency $4 \mathrm{kHz}$

\begin{tabular}{|l|c|c|c|c|}
\hline Factor & Regression coefficient & Effect estimate & Sum of square & \% contribution \\
\hline VE & 0.383 & 0.766 & 2702.947 & 36.73 \\
\hline NL & 0.197 & 0.3094 & 2181.511 & 29.64 \\
\hline VA & -0.418 & -0.836 & 979.573 & 13.31 \\
\hline VE*NL & 0.000 & 0.000 & 1104.957 & 15.01 \\
\hline VE*VA & 0.019 & 0.038 & 93.197 & 1.27 \\
\hline NL*VA & 0.008 & 0.016 & 297.497 & 4.04 \\
\hline VE*NL*VA & 0.000 & 0.000 & 0.000 & 0.00 \\
\hline
\end{tabular}

VA, VE and NL are independent variables of age, years of exposure and noise levels respectively

The normal probability plot of residual of has minimal negligible extensions away from linearity; the model fits the data (Figure 2).

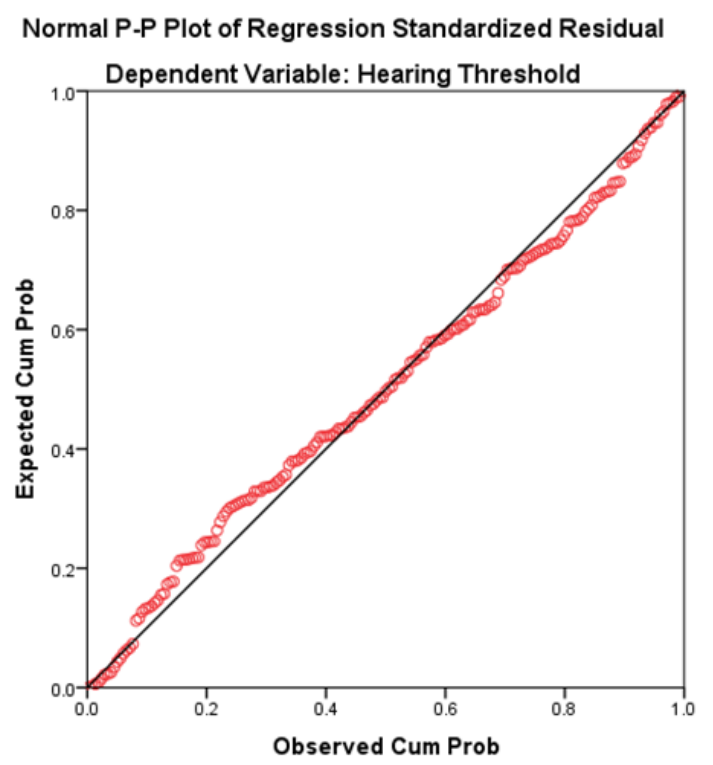

Figure 2: Normal probability plot of standardized residual dependent variable at $4 \mathrm{kHz}$

3.5. Effect of factors of age, years of exposure and noise level on hearing threshold at frequency $6 \mathrm{kHz}$

Table 9 shows that only $\mathrm{F}_{\mathrm{NL}}=7.026, \mathrm{p}<0.05$ is significant with $51.2 \%$ contribution of the variability in hearing threshold (Table 10). None of these factor interactions are significant. The normal probability plot of standardized residual dependent variable proves that the model is good for the data. The value of $\mathrm{R}^{2}=0.229, \mathrm{p}<0.05$ obtained at this frequency is too small, this situation calls for further studies. The model equation:

$H T=-23.072+0.809 N L$

where, 
HT is the Hearing Threshold.

Table 9: Analysis of Variance (ANOVA) of the independent variables at frequency $6 \mathrm{kHz}$

\begin{tabular}{|l|c|c|c|c|c|}
\hline Source & Sum of square & df & Mean square & F & P value \\
\hline Corrected Model & 6922.589 & 22 & 314.663 & 2.270 & $.002^{*}$ \\
\hline Intercept & 559997.767 & 1 & 559997.670 & 403.973 & $.000^{*}$ \\
\hline VE & 386.766 & 3 & 128.922 & .930 & .428 \\
\hline NL & 3895.971 & 4 & 973.993 & 7.026 & $.000^{*}$ \\
\hline VA & 392.388 & 2 & 196.194 & 1.415 & .246 \\
\hline VE*NL & 1538.404 & 7 & 219.772 & 1.585 & .143 \\
\hline VE*VA & 821.660 & 2 & 410.830 & 2.964 & .054 \\
\hline NL*VA & 577.814 & 3 & 192.605 & 1.389 & .248 \\
\hline VE*NL*VA & .000 & 0 & & & \\
\hline Error & 23287.777 & 168 & 138.618 & & \\
\hline Total & 433355.000 & 191 & & & \\
\hline Corrected Total & 30210.366 & 190 & & & \\
\hline \multicolumn{7}{|c|}{ R squared $=.229}$, \\
\hline
\end{tabular}

VA, VE and NL are independent variables of age, years of exposure and noise levels respectively

Table 10: Factor effect estimates and sums of squares for the independent variables at frequency $6 \mathrm{kHz}$

\begin{tabular}{|l|c|c|c|c|}
\hline Factor & Regression coefficient & Effect estimate & Sum of square & \% contribution \\
\hline VE & -5.942 & 11.884 & 386.766 & 5.08 \\
\hline NL & 0.809 & 1.618 & 3895.971 & 51.18 \\
\hline VA & -0.819 & 1.638 & 392.388 & 5.15 \\
\hline VE*NL & -0.074 & -0.148 & 1538.404 & 20.21 \\
\hline VE*VA & -0.016 & -0.232 & 821.660 & 10.79 \\
\hline NL*VA & -0.010 & -0.020 & 577.814 & 7.59 \\
\hline VE*NL*VA & 0.001 & 0.002 & 0.000 & 0.00 \\
\hline
\end{tabular}

VA, VE and NL are independent variables of age, years of exposure and noise levels respectively

3.6. Effect of factors of age, years of exposure and noise level on hearing threshold at frequency $8 \mathrm{kHz}$

Table 11 presents the ANOVA test of Between-Subject Effect. $\mathrm{F}_{\mathrm{VE}}=7.873, \mathrm{p}=0.000, \mathrm{~F}_{\mathrm{NL}}=6.075, \mathrm{p}$ $=0.000$ and $\mathrm{F}_{\mathrm{VA}}=3.293, \mathrm{p}=0.040$ are significant $\left(\mathrm{R}^{2}=0.467, \mathrm{p}<0.05\right)$ with large effects that together account for $77.1 \%$ of the variability in hearing threshold at $8 \mathrm{kHz}$ (Table 12); as years of exposure has the highest contribution of $34.36 \%$ followed by Noise level with $33.39 \%$. None of the factor interaction is significant. The normal probability curve of residual is approximately linear, which indicates the adequacy of the model. The model equation:

$H T=39.489-0.799 V A+0.511 V E-0.022 N L$

where,

HT is the Hearing Threshold.

The normal probability plot of residual is a little skewed on one side; just as other normal probability plots of residual under previous frequencies; there are no outliers. The model is still good for the data (Figure 3).

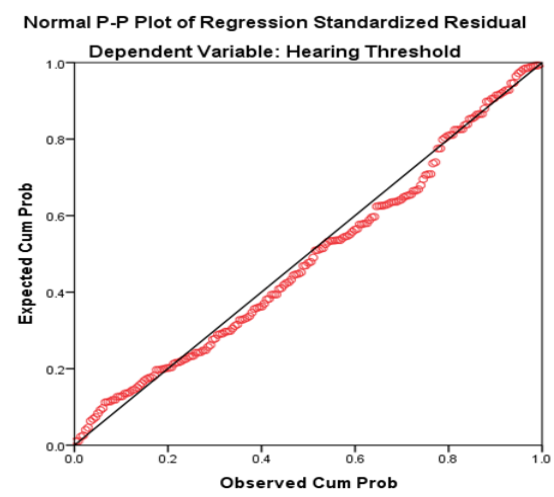

Figure 3: Normal probability plot of standardized residual dependent variable at $6 \mathrm{kHz}$ 
Table 11: Analysis of Variance (ANOVA) for the independent variables at frequency $8 \mathrm{kHz}$

\begin{tabular}{|l|c|c|c|c|c|}
\hline Source & Sum of square & df & Mean square & F & P value \\
\hline Corrected Model & 13076.375 & 22 & 594.381 & 6.693 & $.000^{*}$ \\
\hline Intercept & 53333.103 & 1 & 53333.103 & 600.537 & $.000^{*}$ \\
\hline VE & 2158.156 & 3 & 719.385 & 7.873 & $.000^{*}$ \\
\hline NL & 2097.679 & 4 & 524.419 & 6.075 & $.000^{*}$ \\
\hline VA & 584.971 & 2 & 292.485 & 3.293 & $.040^{*}$ \\
\hline VE*NL & 796.617 & 7 & 113.802 & 1.281 & .262 \\
\hline VE*VA & 395.532 & 2 & 197.766 & 2.227 & .111 \\
\hline NL*VA & 248.509 & 3 & 82.836 & .933 & .426 \\
\hline VE*NL*VA & .000 & 0 & & & \\
\hline Error & 14919.918 & 168 & 88.809 & & \\
\hline Total & 481408.00 & 191 & & & \\
\hline Corrected Total & 27996.293 & 190 & & & \\
\hline \multicolumn{7}{|c|}{ R Square $=.467$} \\
*P $<0.05$
\end{tabular}

VA, VE and NL are independent variables of age, years of exposure and noise levels respectively

Table 12: Factor effect estimates and sums of square for the independent variables at frequency $8 \mathrm{kHz}$

\begin{tabular}{|l|c|c|c|c|}
\hline Factor & Regression coefficient & Effect estimate & Sum of square & \% contribution \\
\hline VE & 0.511 & 1.022 & 2158.156 & 34.36 \\
\hline NL & 0.022 & 0.044 & 2097.679 & 33.39 \\
\hline VA & -0.799 & -1.598 & 584.971 & 9.31 \\
\hline VE*NL & -0.006 & -0.012 & 796.617 & 12.68 \\
\hline VE*VA & 0.022 & 0.044 & 395.532 & 6.30 \\
\hline NL*VA & 0.013 & 0.026 & 248.509 & 3.96 \\
\hline VE*NL*VA & 0.000 & 0.000 & 0.000 & 0.00 \\
\hline
\end{tabular}

VA, VE and NL are independent variables of age, years of exposure and noise levels respectively

The model is appropriate for the data as the normal probability plot of residual is approximately linear (Figure 4). The present study investigated the physiological response of quarry workers working in noisy environment. Amount of noise emitted by various equipment which workers were exposed to during work in selected quarries were estimated. The noise measurement values in this study were in the range of $28.4 \mathrm{dBA}$ in the administrative section to $116.98 \mathrm{dBA}$ in the production section. The mean hearing threshold among all workers in the quarry was $27.9 \mathrm{dBA}, 51.7 \%$ had hearing threshold level higher than 25dBA. The differences between the mean values of hearing threshold level of the respondents of the four quarries are not significant $(\mathrm{F}=1.068, \mathrm{P}=0.364)$ which indicated that all the quarries were subjected to about the same working conditions and environmental noise. There is a stronger linear relationship between the average hearing loss over the frequencies $3 \mathrm{kHz}$ through $8 \mathrm{kHz}$, and the age of workers, years of exposure and noise level. Seventy percent of the variation in hearing threshold is sought in and explained by the factors variables. Therefore $30 \%$ variation in hearing loss is explained by variable not figured in the model. The maximum association between hearing loss and age, years of exposure and workstation at $4 \mathrm{kHz}$ indicates a dip notch at the characteristic frequency. This is in agreement with Akanbi and Oriolowo (2016). It can be concluded that a number of the respondent may have been exposed to areas with high noise levels in the $4 \mathrm{kHz}$ frequency. There was also a relationship between hearing loss, and age at all workstations with the degree of association between 0.6 and 0.9 ; also with years of exposure between 0.5 and 0.9 .

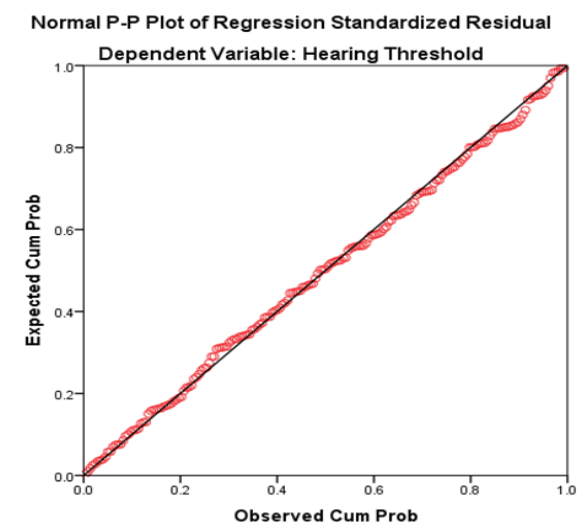

Figure 4: Normal Probability plot of standardized Residual Dependent variable at $8 \mathrm{kHz}$ 


\subsection{Conclusions}

It can be concluded that most of the machines used in quarry operation produces noise level in the range of $87.3-116.9 \mathrm{dBA}$ which is greater than the acceptable threshold sound level; except in the administrative section where the noise level is $28.4 \mathrm{dBA}$ which is lesser than the acceptable threshold of $85 \mathrm{dBA}$. The discrepancies between the noise level in the administrative block and quarry section also indicates the proneness of the workers at quarry section to the higher hearing threshold than the administrative workers. This study has established statistically that all respondents' at all four different quarries were subjected to about the same working conditions and environmental noise level. The study further revealed the impacts of the age, years of exposure and noise level on the hearing threshold across some frequency which is used in modelling formulation. The contributions of each independent variable and their interactive effects on the dependent variables were spelt out at the various frequencies. At frequency $4 \mathrm{kHz}$ and $8 \mathrm{kHz}$, there is only main effect contribution of age, years of exposure and noise level with no interactive effect indicating that the 3 factors mentioned can independently predict the hearing threshold of the workers. Only main effects of years of exposure and noise level are the determining factors on the hearing threshold of workers at frequency $3 \mathrm{kHz}$; while only the noise level as main variables at the frequency $6 \mathrm{kHz}$ can determine the hearing threshold of the workers. Conclusively, the degree of predictors and contribution of Noise level > Years of exposure > Age to the hearing threshold at 3,4,6 and 8kHz. These finding are of concern to the researcher in order to have the independent variables data before embarking on recruiting workers to be working in noisy environment in order to protect their hearing status.

\section{Acknowledgement}

The authors are grateful to the Management of the Quarries used for the conduct of this research: Ladson Quarry, Alleluyah Quarry, MPC Quarry and Ilugun Quarry; and Engr. Busari of Human Factor Engineering Laboratory of Industrial and Production Engineering Department, University of Ibadan.

\section{References}

Abe, T., Soer, M. and Abiodun, K. (2009). Effect of use of personal hearing protective devices among oil Depot Industrial Workers in Lagos, Nigeria. Nigerian Journal of Medical Rehabilitation (NJMR), 14(1), pp. $22-32$.

Akanbi, O. G. and Oriolowo, K. T. (2016). Modeling the Prevention of Transformation of Pressbycusis to Noise Induced Hearing Loss. Journal of Nigerian Institute of Industrial Engineers (NIIE), 6, pp. 47-58.

Akeroyd, M.A., Foreman, K., and Holman, J. A. (2014). Estimates of the number of adults in England, Wales and Scotland with a hearing loss. International Journal of Audiology, 53(1), pp. 60 67.

Allen, P. D. and Eddins, D. A. (2010). Presbycusis phenotypes form a heterogeneous continuum when ordered by degree and configuration of hearing loss. Hear Res, 264, pp. 10-20.

Al-Magharabi, M.N., Shewakh, W. M. and Halem, A. (2013). Degradation of Industrial Performance due to environmental factors: Impacts of Noise on Mining and Manufacturing workers. International Journal of Mechanical and Production Engineering Research and Development (IJMPERD), 3(2), pp. 147 - 154.

Bainbridge, K. E., and Wallhagen, M. I. (2014). Hearing Loss in an aging America population: extent, impact and management. Annu Rev Public Health, 35, pp. 139-152.

Biassoni, E. C., Serra, M. R., Hinalaf, M., Abraham, M., Paylik., M. and Villalobo, J. P. (2014). Hearing and loud music exposure in a group of adolescent at the ages of 14-15 and retested at 17-18. Noise Health, 16(72), pp. 331-341. 
Bouloiz, H., Garbolino, E., and Tkiouat, M. (2013). Modeling of an Organizational Environment by System Dynamics and Fuzzy Logic. Open Journal of Safety Science and Technology, 3, pp. 96-104. http://dx.doi.org/10.4236/ojsst.2013.34012.

Contrera, K.J., Bertz, J., Genther, D.J. and Lin, F.R. (2015). Association of hearing impairment and mortality in the National Health and Nutrition Examination Survey.JAMA Otolaryngol Head Neck Surg, 141, pp. 944 - 946.

Durakovic, B. (2017). Design of Experiments Application, Concepts, Examples: State of Art. Periodicals of Engineering and Natural Sciences, 5(3), pp. 421- 439.

England, B., and Larsen, J.B. (2014). Noise Levels among Spectators at an intercollegiate sporting event.Am J Audiol, 23(1), pp. 71-78.

Fisher, D., Li, C.M., and Chiu, M.S. (2014). Impairments in hearing and vision impact on mortality in older people: the AGES-Reykjavik Study. Age Ageing, 43, pp. 69 - 76.

Gallacher, J., Ilubaera, V., and Ben-Shlomo, Y. (2012). Auditory Threshold, phonologic demand, and incident dementia. Neurology, 79, pp. 1583-1590.

Genther, D. J., Frick, K.D., Chen, D., Betz, J., and Lin, F.R. (2013). Association of hearing loss with hospitalization and burden of disease in older adults. JAMA, 309, pp. 2322-2324.

Hong, O., Kerr, M. J. Poling, G. L., and Dhar, S. (2013). Understanding and Preventing Noise Induced Hearing Loss. Dis Mon, 59(4), pp. 110-118.

Howard, J. H., Robert, A. D., Katalin, G. L., Christa, L., Themann, M. A., and Gregory, A. F. (2017). Declining Prevalence of Hearing Loss in US Adults Aged 20 to 69 years. JAMA Otolaryngol Head Neck Surg, 143(3), pp. 274-285.

Ibraheemm, O. A. and Hassaan, M. R. (2016). Psychoacoustic characteristics of tinnitus versus temporal resolution in subjects with normal hearing sensitivity. Int Arch Otorhinolarryngol.20. https://doi.org/10.1055/s-0036-1583526.

Kamil, R. J. and Lin, F.R. (2015). The effects of hearing impairment in older adults on communication partners: a systematic review. J Am AcadAudiol, 26, pp. 155-182.

Karvana, G., Venkatappa, V. S., and NachalAnnamalia, M.S. (2012). Assessment of Knowledge, Attitude and Practices of Traffic Policemen regarding the auditory effects of Noise. Indian J. Physiolpharmacol, 56(1), pp. 69-73.

Lobarinas, E., Salvi, R. and Ding, D. (2013). Insensitivity of the audiogram to carbon plating induced inner hair cells loss in Chinchillas.Hear Res, 302, pp. 113-120.

Li, C. M., Zhang, X., Hoffman, H. J., Cotch, M. F., Themann, C. L. and Wilson, M. R. (2014). Hearing Impairment associated with depression in US adults, National Health and Nutrition Examination Survey 2005-2010. JAMA Otolaryngol Head Neck Surg, 140, pp. 293-302.

Lin, F.R., Metter, E.J., O’Brien R. J.,Resnick, S.M., Zonderman, A.B. and Ferrucci, L. (2011): "Hearing Loss and incident dementia. Arch Neurol, 68, pp. 214-220.

McBride, D.I. (2004). Noise Induced Hearing Conversation in Mining.Occup Med (Long), 54(5), pp. 290-296.

Mener, D.J., Bertz, J., Genther, D.J., Chen D. and Lin, F.R. (2013). Hearing loss and depression in older adults. J Am GeriatrSoc, 61, pp. 1627-1629. 
Mick, P., Kawachi, I. and Lin, F.R. (2014). The association between hearing loss and social isolation in older adults. Otolaryngol Head Neck Surg., 150, pp. 378-384.

Montgometry, D.C. (2013). Design and Analysis of Experiments. John Wiley \& Sons, Inc., $8^{\text {th }}$ ed.

Ojolo, S.J. and Ismail, S.O. (2011). Mathematical Modeling of effects of Noise on Machine Operators. Proceeding of International Conference on Innovation in Engineering and Technology, pp.78-90.

Onder, M., Onder S. and Mutlu, A. (2012). Determination of Noise Induced Hearing Loss in Mining: an application of Hierarchical log linear Modelling. Environ Monitoring Assessment, Springer, 184, pp. 2443-2451.

Onsekizoglu, P., Bahceci, K.S. and Acar, J. (2010). The use of factorial design for modelling membrane distillation. Journal of Membrane science, 349, pp. 225 - 230.

Ridzuan, N., Adam, F. and Yaacob, Z. (2016). Screening of factor influencing wax deposition using full factorial experimental design. Petroleum Science and Technology, 34(1), pp. 84-90.

Solanki, J. D., Mehta, H. B., Shah, C. J. and Gokhale, P. A. (2012). Occupational Noise Induced Hearing Loss and Hearing Threshold Profile at High Frequencies. Indian Journal of Otology, 18(3), pp. $125-128$.

Starr, A., and Rance, G. (2015). Auditory Neuropathy. HandbClinNeurol, 129, pp. 495-508.

Williams, W., Purdy, S., Murray, N., Lepage, E., and Challinor, K. (2004). Hearing Loss and Protection of Noise in the workplace among Rural Australians. Aus. Rural Health, 12(3), pp. 115-119. 